\title{
Dyslexia in Children -A Brief Review
}

Malleedi shanthi ${ }^{1}$

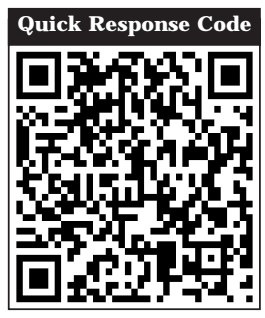

doi: 10.5866/2014.611456

'Senior Lecturer

Department of Paediatric \& Preventivr Dentistry

Mamata Dental College \& Hospital

Giriprasad Nagar,

Khammam

\section{Article Info:}

Received: October 13, 2013

Review Completed: November 12, 2013

Accepted: December 11, 2013

Available Online: February, 2014 (www.nacd.in)

(C) NAD, 2014 - All rights reserved

Email for correspondence:

shanthineha2012@gmail.com

\begin{abstract}
:
Dysl exia is a form of language-based learning disability. It refers to a cluster of symptoms, which result in people having difficulties with specific language skills, particularly reading. Though it is a life-long status, its impact can change at different stages of child's life. Dyslexia in children manifests in the form of hyperactivity and nervousness. This makes cooperation for dental procedures difficult. Most of the children can be treated for routine dental procedures with slight modifications, expect some require use of physical restraints, conscious sedation or general anesthesia if child resists dental treatment. This paper gives a brief review on definition, aetiology, clinical features, diagnosis, and management of dyslexic child.
\end{abstract}

Key words: Cognition, Disabled child, Impairment, Learning Disability.

\section{Introduction:}

All children are unique and are influenced by cultural, linguistic, intellectual, psychological, medical, social and economic factors. A disorder is one or more of the basic psychological processes involved in understanding or in using language, spoken or written, that may manifest itself in the imperfect ability to listen, think, speak, read, write, spell, or do mathematical cal culations, including conditions such as perceptual disabilities, brain injury, minimal brain dysfunction, dyslexia, and developmental aphasia. Specific learning disability does not include learning problems that are primarily the result of visual, hearing, or motor disabilities, of mental retardation, of emotional disturbance, or of environmental, cultural, or economic disadvantage.

Dyslexia is a biologically determined learning disability ${ }^{1}$ in children. It is a very common learning difficulty, affecting a large percentage of those label ed "learning disabled." According to the National Institutes of Health, out of $15 \%$ with dyslexia in U.S. population, $3-10 \%$ is school going age. Dyslexia occurs among 
people of all economic and ethnic backgrounds. Three times as many boys as girls have dyslexia.

\section{Etiology 2}

\section{Some of the possible factors are:-}

- The dyslexic brain is different from ordinary brains in the anatomy, organization and functioning. They tend to be more 'right brain thinkers'. The right hemisphere of the brain ${ }^{3}$ is associated with lateral, creative and visual thought processes.

- Dyslexia is not related to race, social background or intellectual ability but there is a tendency for dyslexia to run in families and this suggests that the brain differences which cause dyslexia may be hereditary.

- Neurological differences ${ }^{4}$ have the effect of giving the dyslexic person a particular way of thinking and learning. This usually means that the dyslexic person has a pattern of cognitive abilities which shows areas of strengths and weaknesses.

- Replicated linkage studies implicate loci on chromosomes 2, 3, 6, 15, and 18.

\section{Epidemiology 5}

Current studies suggest that $15-20 \%$ of the population has a reading disability. Of those, $85 \%$ has dyslexia. Dyslexia occurs in people of all backgrounds and intellectual levels. In addition, dyslexia runs in families and heritable; dyslexic parents are very likely to have children who are dyslexic. Some children are identified as dyslexic early in their lives, but for others their dyslexia goes unidentified until they get older. Children who are very bright can be dyslexic. Thus, up to $50 \%$ of children of dyslexic parents, $50 \%$ of siblings of dyslexic children, and $50 \%$ of parents of dyslexic children may have the disorder.

\section{Clinical features ${ }^{6}$}

The impact that dyslexia has is different for each person and depends on the severity of the condition and the approaches of the remediation. Some common problems are:-

- $\quad$ Short attention spans
- Distractibility

- Hyperactivity

- Mild speech impairment

- Difficulty in reading, spelling, spoken language and writing

Some dysl exics do not have much difficulty with early reading and spelling tasks but do experience great problems when more complex language skills are required, such as grammar, understanding textbook material, and writing essays.

\section{- Child with poor self-esteem ${ }^{7}$}

Students with dyslexia often end up feeling "dumb" and less capable than they actually are. After experiencing a great deal of stress due to academic problems, a student may become discouraged about continuing in school $\bullet$ Social interaction is poorly developed due to difficulty in spoken language

They may find it difficult to express them clearly, or to fully comprehend what others mean when they speak

- Anxiety and lack of confidence

- Organization is disoriented.

\section{Diagnosis $^{8}$}

Mainly by clinical via history and observation. Additional method includes psychometric assessment, neurological examination, laboratory measures such as imaging studies, electro encephalography, and chromosomal analysis.

\section{Management $\mathbf{t}^{9,10,11}$}

\section{Parent's Role}

All children need love, encouragement, and support, and for kids with learning disabilities, such positive reinforcement can help ensure that they emerge with a strong sense of self-worth, confidence, and the determination to keep going even when things are tough. To give a child, social and emotional tools he or she needs is to work through challenges. In the long run, facing and overcoming a challenge such as a learning disability can help your child grow stronger and more resilient. 


\section{Paediatrician and Child Psychologist Role}

Increasingly, Paediatrician and Child Psychologist need to respond to parents' requests for help when a child is experiencing difficulties in school. The requests may be related to the child's academic progress, or ability to attend and concentrate or to interact and respond appropriately at school. Parents frequently look for help, guidance and advice. Schools often request assessment of underlying medical, family and/or emotional problems, or request further referrals regarding a child who is experiencing difficulty concentrating or learning. Because these assessments involve the integration of information from a variety of sources, it is necessary to set aside considerable time to focus on what are often complex problems.

\section{Paediatric Dentist Role}

Oral health of children with disabilities is different from normal peers, for example of greater prevalence of dental caries, periodontal diseases, occlusal wear. Prevention of dental diseases in disabled children needs to be a higher priority. Dentist should be patient and use a slow approach to the oral cavity. Short and morning appointments are preferred. Most of them can betreated in dental surgery in normal way with slight modifications as discussed below.

\section{Consent for dental care}

Treatment plan for children below 16yrs of age requires consent from parent before starting active treatment. The British society of disability and oral health's policy document on physical interventions clearly stated consent is required for adolescent above 16yrs with impairment.

\section{Home care}

Parent's need specific advice and practical help to care for child's mouth. Great reliance must place in oral hygiene instructions and modifications to standard techniques. Modification to the existing tooth brushes like use of infabrush, super brush is advised. Regular reinforcement of oral hygiene instruction should be done.

\section{Diet}

General dietary advice like restrict sweet foods or drinks to meal times, limited sweetened food or drinks to three times a day, keep food and drinks clear of bed time by about an hour, use of sugar free medications are advised.

Behaviour management techniques like tellshow-do (TSD), positive reinforcements (social, material, activity) and rewards may be helpful in some children.

Other preventive measures like use of Duraphat fluoride varnish ( $5 \%$ sodium fluoride $=22,600 \mathrm{ppm}$ fluoride) is an ideal preventive agent for children with poor oral hygiene.

Human clinical trails in some countries are investigating use of intra-oral fluoride releasing device. This device is attached to buccal surface of tooth with composite resin. They continue to el evate salivary fluoride levels. The placement and retention in situ of such device is challenge for paediatric dentist.

Fluoride supplements are also best option to give optimal caries protection. F or low risk children 500-6-ppm of $F$ paste ( $<6 y r s)$ and 1000-1500ppm of $F$ paste ( $>6 y$ rs). F or high risk $1000-1500 p p m$ of $F$ paste (pea-sized amount) from the time of tooth eruption is advisable.

Most of the traditional behaviour management methods may work and the paediatric dentist may be left with physical restraints and pharmacological behavior managements to provide high quality dental care.

A child with impairment presents dental team a challenge for examination as well as treatment procedures. It is important that every effort should maketo optimize oral function and facial appearance and thereby encourage a positive self-image. Some degree of flexibility, working familiarity with common oral conditions is required to provide optimal dental care for child with impairment.

"Dyslexia is not a disease to haveand to becured of, but a way of thinking

and learning. Often it's a gifted mind waiting to be found and taught." 


\section{Table 1: Dyslexia: Warning Signs By Age}

\section{Young Children}

Trouble With:

- Recognizing letters, matching letters to sounds and blending sounds into speech

- Pronouncing words, for example saying "mawn lower" instead of "lawn mower"

- Learning and correctly using new vocabulary words

- Learning the alphabet, numbers, and days of the week or similar common word sequences

- Rhyming
School-Age Children

Trouble With:

- Mastering the rules of spelling

- Remembering facts and numbers

- Handwriting or with gripping a pencil

- Learning and understanding new skills; instead, relying heavily on memorization

- Reading and spelling, such as reversing letters $(d, b)$ or moving letters around (left, felt)

- Following a sequence of directions

- Trouble with word problems in math's
Teenagers and Adults

Trouble With:

- Reading at the expected level

- Understanding nonliteral language, such as idioms, jokes, or proverbs

- Reading aloud

- Organizing and managing time

- Trouble summarizing a story

- Learning a foreign language

- Memorizing

\section{References}

1. Richton J \& Dunn H. Learning Disabilities: A Practical Office Manual. 2nd edn. Canadian Paediatric Society; 1982.

2. Francis DJ, Shaywitz SE, Stuebing KK, Shaywitz BA, Fletcher J M. Developmental lag versus deficit models of reading disability: A longitudinal, individual growth curves analysis. J Educ Psychol 1996; 88:3-17.

3. Shaywitz SE, Shaywitz BA, Pugh KR, et al. Functional disruption in the organization of the brain for reading in dyslexia. Proc Natl Acad Sci USA 1998; 95:2636-2641.

4. Shaywitz S. Current concepts: dyslexia. N Engl J Med 1998;338:307-312.

5. Shaywitz SE, Fletcher J M, Holahan J M et al. Persistence of dyslexia: The Connecticut Longitudinal Study at Adolescence. Pediatrics. 1999; 104:1351-1359.

6. Sally E. Shaywitz, \& Bennett A. Shaywitz, Dyslexia (Specific Reading Disability) Pediatrics in Review 2003; 24(5): 147-152.
7. Catherine Lam. Dyslexia and other Specific Learning Disabilities. Special feature 2001; 6(3).

8. Aaron PG, J oshi M, Gooden R, and Bentum K. Diagnosis and treatment of reading disabilities based on the component model of reading: An alternative to the discrepancy model of LD. J ournal of Learning Disabilities 2008; 41:67-84.

9. Catts HW. Defining dyslexia as a developmental language disorder: An expanded view. Topics in Language Disorders 1996;16(2):14-29.

10. Cramer SC, Ellis W. Introduction. Learning Disabilities: Life Long I ssues xxvii-xxxi. Brookes 1996.

11. Nunn J H (2003). Preventing childhood impairment. In the prevention of oral disease (4 ${ }^{\text {th }}$ edn). (eds. J J .Murray, J.H Nunn, and J.G.Steele), pp. 200-16. Oxford Medical Publications, Oxford.

\section{Gain quick access to our journal online View our journal at www.nacd.in}

